\title{
1. Introduction: valuing the developing world environment
}

\section{David Pearce}

The science of environmental economics is concerned with an array of issues, but they can be conveniently summarized as: (a) measuring the 'state of the environment' in terms of how people feel about their surroundings, (b) assessing the causes of environmental degradation, and (c) designing incentive-based policies for improving the environment. In each case the economic perspective differs markedly from what other disciplines would do if confronted with the same issues. A scientist would measure, say, emissions of air pollutant and their atmospheric concentration. This would be a measure of the 'state' of the environment. Causes would most probably be assessed by scientists and most social scientists in terms of 'who does what'. Thus a slash-and-burn agriculturist, or a logging company, would be seen as the 'cause' of the problem of deforestation. To the economist this identification of the proximate agent is not what is meant by a cause. Real, or fundamental, causes relate to the incentive systems that give rise to deforestation; that is, what drives the logger to behave as he does, and why does the agriculturist do what he does? To the economist, the answers lie in the many, varied and frequently contradictory signals that economic systems and governments relay to the proximate agent. It might be a subsidy that is contingent on clearing forest land, or the sale of a forest concession to $\log$ which does not reflect the true costs of logging. From this analysis of causes it also follows that the economic approach tends to identify different policy prescriptions to other disciplines. Traditional policies tended to focus on bans or quotas, limits and standards. The policy was 'obey this or face the following consequence', or 'command and control'. Today some disciplines seem content with calling for more participation and 'stakeholder dialogue'. Both are important but neither is a recipe for success unless accompanied by a careful analysis of the true causes of environmental degradation. In turn, policy has to address those causes, not the cosmetic issues, or, dare one say, the 'politically correct' issues. Policy is therefore likely to be directed towards definitions and arrangements of property rights, prices, removal of price disincentives, information and reform of governance. 
Probably the most controversial of the stages in the three-part sequence of the economic approach is the way economists assign importance to the state of the environment. Crudely put, the more people care about an issue the more important it is. The economist's approach to measuring the state of the environment is therefore based on human preferences. Scientific measures of environmental trends are important, but they are the object of what people care about. They do not therefore measure the state of the environment, whereas scientific information coupled with preference measurement does measure the state of the environment. A surprising number of scientists are wholly or partly indifferent to what people care about. This indifference often stems from scientific arrogance - the feeling that experts 'know better' than the 'common man'. But some attitudes stem from a belief that, if humans are to survive and prosper on this earth, we cannot trust human preferences to ensure that survival will occur. Nowhere is that view more strongly expressed than in much of the literature on 'sustainable development', a notion of an economic and social development path that tries to ensure a lasting rise in human well-being. The problem is that many advocates of sustainable development confuse 'sustainability' with 'survivability'. The latter is hardly worth the candle if survival entails increasing immiseration. Focus on the notion of human well-being and its sustained increase over time would avoid this confusion and its anti-democratic overtones. Again, this is why economists (in the main - many of them fall into the same trap) emphasize the role played by human preferences.

If preferences are central, how are they measured? The economist brings to bear on this question the whole panoply of welfare economics and the formal links that it establishes between preferences and willingness to pay for a benefit and willingness to accept compensation for a loss. This is the cornerstone of cost-benefit analysis. It has its faults but, to date, no other evaluation procedure comes close to it in terms of theoretical coherence. The idea of measuring preferences as an input to cost-benefit approaches has been around in economics since Jules Dupuit thought about how to justify the costs of roads and bridges in France in the 1840s. Not surprisingly, therefore, there is a vast literature covering the technical issues and case studies in developed economies. The application of cost-benefit approaches in the developing world is far more recent. The major texts emerged in the late 1960s and into the 1970s (Marglin et al., 1972; Little and Mirrlees, 1974; Squire and van der Tak, 1975). But none of these texts dealt with environmental assets, despite the fact that environmental destruction has been extraordinarily rapid in the poorer world. Moreover, that destructive process has had substantial negative effects on human well-being. The neglect of environment in developing country cost-benefit analysis, which is mirrored today in a widespread ignorance of environmental economics 
among development economists, was therefore serious. It has since been rectified in the environmental economics literature, though not, sadly, in most of the development literature.

One issue that may explain the neglect of environmental economics in development work extends the notion of the irrelevance of preferences to decision making in general. If people in rich countries cannot be trusted with their own futures, how can we trust people who are poor, ill-informed and generally preoccupied with the problems of survival? Oddly, this view is often accompanied by the contrary assumption that poor people must always be consulted about their future, a wholly correct approach but one which seems to stop short of actually measuring their preferences. In the early days of environmental economics in developing countries it was quite common to come across the view that 'cultural' differences made the use of economic valuation inappropriate or unworkable in poor countries. The contributions to this volume are testimony to the error of this assumption. They are all concerned, in one way or the other, with the measurement of preferences for environmental change.

The current volume is one of two, the first dealing with the developing world and the second of which will deal with the developed world. Most, but not all, of the contributions come from authors who have at one time or the other worked in the Centre for Social and Economic Research on the Global Environment (CSERGE) at University College London, in association with the University of East Anglia. CSERGE was founded in 1991 on the basis of the 'state-cause-policy' paradigm identified above. By and large, CSERGE's work has been driven by economic analysis. Hence the current volume is focused entirely on economic approaches. The range of applications is very wide, from water quality to air pollution, from wetlands to wildlife tourism. The common theme is that economic valuation based on what people want is perfectly feasible in the developing world. None of the authors pretends that the techniques they adopt are perfect, but they show how they can be applied, often with limited resources, to critical issues in development. A second theme, which is in no way a logical consequence of measuring preferences, is that environmental assets are important - the resulting economic valuations are often large relative to the opportunity cost of surrendering the environmental resource. Third, some of the chaptors show that the 'non-market' benefits of the assets in question are especially important for low income groups. It is a common error to find 'income' being measured by wages or receipts from the sale of crops, the apparently non-monetized benefits that many poor people get from environmental resources being ignored. Fourth, but only implicit in most of the chapters, what local people are willing to pay for the conservation of environmental assets may be a small fraction of global willingness to pay. 
People in developed economies are willing to pay a lot to be tourists in wildlife-rich countries, and many will pay simply to conserve the asset in question without any probability that they will actually see the asset. This non-use value does much to explain donations to charities that specialize in environmental conservation in the developing world.

Why might rich people's valuations be relevant to developing country conservation policy? Because valuation is only one stage of a two-stage process. If we can demonstrate how important the environment is in terms of willingness to pay, then the next stage is to devise ways in which those valuations can be realized as cash flows. The issue is to design 'capture' mechanisms. A cost-benefit analysis does not concern itself with capture mechanisms - that is, means of converting non-monetary benefits to cash flows. If benefits exceed costs, that is sufficient cause to recommend conservation. But for a great many policy contexts, costs and benefits matter only if they are associated with real resource flows. Capture mechanism design is therefore critical if, say, the black rhinoceros or the Chinese panda is to avoid extinction.

One other theme is relevant. A great deal of interest has been shown in recent years in the idea of extending national income accounts to reflect environmental asset change. Forests can be depleted and GNP might actually rise. But the rise masks a reduction in the underlying stock of economic assets since the forest stock is a constituent part of those assets. It is therefore important to set the record straight and include the depletion of the forest as a loss of real wealth. Amending income accounts in this way seems worthwhile, but its usefulness should not be exaggerated. Far too many politicians have not understood what modifying the national accounts means, and far too many believe that, once they have been modified in some way, economic decisions will change. There is no real evidence to support this view.

Economic valuation thus has many uses. It can be used to modify national income accounts; it can be used as an essential ingredient of cost-benefit analysis; often overlooked, it can be used to signal that an issue is important in economic terms, an argument that is sometimes powerful when the person to be persuaded is the minister for finance. In the rich world it can be used to measure damage liability and to set environmental taxes, both uses also being relevant to the developing world as the transition to higher incomes comes about and environmental institutions grow.

\section{REFERENCES}

Little, I. and J. Mirrlees (1974), Project Appraisal and Planning for Developing Countries, London: Heinemann. 
Marglin, S., A. Sen and P. Dasgupta (1972), Guidelines for Project Evaluation, Vienna: United Nations Industrial Development Organisation.

Squire, L. and H. van der Tak (1975), Economic Analysis of Projects, Baltimore: Johns Hopkins University Press. 
David Pearce - 9781781950968 Downloaded from PubFactory at 04/26/2023 02:41:33PM via free access 